DOI: $10.20472 / \mathrm{TE} .2019 .7 .1 .003$

\title{
CLASS DOJO AND STUDENT SELF-REGULATION: AN EXAMINATION OF BEHAVIOR PATTERNS AND ACADEMIC OUTCOMES
}

\section{BERNARD CHARLES}

\begin{abstract}
:
This paper focuses on the impacts of Positive Behavior Intervention Supports (PBIS/PBI/PBS) on the progression of positive student behavior traits. Specifically, there will be a focus on the ways that PBIS impact student behaviors in the classroom. The research will focus on: the benefits and detriments of enacting PBIS into the classroom, the role PBIS can have on the academic outcomes of students, and the role technology can have in promoting student self-regulation in the 21st century. In conducting this study, the goal is to connect my desired research with that of prior analysis to support my argument that PBIS is essential to positive classroom and school culture that fosters educational success in all learning environments.
\end{abstract}

\section{Keywords:}

Positive Behavior Intervention (PBI)

Positive Behavior Intervention Supports (PBIS)

Kuwait

affluent

low-income

students

high-performing

low-performing

education

private schools

JEL Classification: $A 12, A 13, D 71$

\section{Authors:}

BERNARD CHARLES, N/A, United States, Email: mr.charlesstudies@gmail.com

\section{Citation:}

BERNARD CHARLES (2019). CLASS DOJO AND STUDENT SELF-REGULATION: An Examination of Behavior Patterns and Academic Outcomes. International Journal of Teaching and Education, Vol. VII(1), pp. 14-40., 10.20472/TE.2019.7.1.003 


\section{Research Background}

Context: My school is located in Khaitan, Kuwait. It is a suburb outside of Kuwait City, the capital of Kuwait. The school is composed of $98 \%$ ethnic Kuwaitis and $2 \%$ are other Arab nationals. The school is a private school tuition based school. The school is segregated into a girl's campus and boy's campus after $5^{\text {th }}$ grade. I served as an educator in high school social studies. There are several groups for students to gain extracurricular experience. However, little control is actually in the hands of students. The level of parent involvement, even with the high tuition and recognition of the importance of schooling, is lackluster. Parents for high school students make little effort to communicate with teachers. They are usually traveling or detached from their child's schooling aside from financial support. Students are often left under the care of nannies. As a result, whether direct or indirect student behavior resembles that of a low-income urban school with similar parental involvement levels. There is excessive talking, playing, disregard for daily lessons, and at times an overall indifference toward schooling.

Challenge: I intend to determine the impacts of positive behavior intervention supports (ClassDojo and student of the week award) on influencing student behavior within my classroom. It is my goal to determine whether $10^{\text {th }}$ grade students, deemed misbehaving by most teachers and administrators, will increase their display of positive behavior as a result of the supports implemented. Along with positive behavior, there will also be an investigation of the impacts of PBI on academics. In order to check impacts students and parents will have differing accounts on ClassDojo to monitor student behavior. The desired outcome will feature an improvement in student behavior toward one another, better engagement within class, academic growth and a better sense of community within the classroom.

Justification: This is a critical topic for teachers of all grade levels. The general idea is that students at private schools do not display negative behaviors and money solves educational issues. However, one can argue that students display similar behaviors just at different levels, which impacts educational outcomes. An existing and reoccurring barrier to educational success is negative behavior problems, therefore schools need a beneficial action plan. In most cases, teachers need their own unique set of systems. As it regards my current school, there is no such plan, as detentions and suspensions have proven ineffective in reducing negative behavior. As an educator, it is part of my responsibility to manage and correct negative behavior as well as promote positive behavior. Additionally, these tactics can be applicable to schools regardless of environment as it can demonstrate the impacts these interventions can have within a private high school setting and can be adapted. It is also important to check the outcomes of these systems in a setting that has limited data regarding student behavior and intervention impacts. It can demonstrate a manner to address negative behavior from even the "bad" kids without alienating or demoralizing themperhaps even turning them into agents of change.

\section{Research Question:}

How does an implementation of positive behavior interventions influence student behavior?

\section{Sub-Research:}

Does this system change student classroom awareness and overall engagement?

Is there an increase in academic performance? 
Is there any carry over into other classes?

What happens to behavior after the program is removed?

\section{Conceptual Background and Research}

Several studies (Putnam, Hormer \& Algozzine, 2011; Polirstok \& Gottlieb, 2006; Sugai \& Horner, 2009; Bohanon et al., 2006) have been conducted to investigate the necessity of PBI and their impacts within schools. These studies analyze how teachers implement PBI and the ways the school community is altered, as a result. However, only a small amount of studies (Pound, 2013; Singer 2014) focused on inserting $21^{\text {st }}$ century technologies into PBI. The benefits of merging technologies to connect school and home life cannot be ignored. As Kazepides states, "our goal is to design a better environment as the environment is critical not the person" (Kazepides, 1976, p. 56). These strategies should be implemented to provide a better outcome regardless of demographic. The practices of PBIS can be used within all schools to create a structured environment. The idea that high-income, private schools cannot be served by PBIS perpetuates the belief that these demographics are performing optimally.

I argue that students that are financially affluent students in a private school should have the same recognition relating to PBIS and its impacts on their development as students from lower-income schools. Schooling can often be seen as a scheduled task. It is something that students are to complete without regard for the benefits offered. However, students are not a monolith and utilize schooling as a means for varying outcomes. As a result, indifferent or negative behaviors related to school can have a detrimental impact on their lives. It is crucial to provide students an environment that is conducive to learning and collective growth. The purpose of this study is to provide insight on incorporating PBIS into a private school setting, with mostly affluent students and evaluate its impact on improving positive behavior and developing a better classroom environment.

\section{Literature Review}

This literature review analyzes the impacts of implementing Positive Behavior Intervention Supports (PBIS) into schools. My inquiry project explores the impacts in implementing PBI in the classroom to increase positive behavior and develop a better classroom environment. I argue that students from affluent schools are placed at a disadvantage when not offered tools to influence positive behavior development. The goal is to learn the results and prior understanding of enacting PBIS in schools and the strategies used to track outcomes of prior research. Synthesis will be conducted on implementing the program as it regards varying school levels, potential benefits and detriments, the correlation to academic achievement, and the role technology has in behavior management in schools. Each has an impact in school success for teachers, parents, students, and society as a whole. As students are prepared to be citizens of the world, we must first learn collectively the role behavior has in shaping the student perspective.

\section{Positive Behavior Intervention}

Behavior in the classroom has a critical impact on educational outcomes; research has shown that several factors impact student behavior within the classroom (Rhule, 2005; Putnam, Horner, and Algozzine, 2011; MacLean-Blevins, 2013; Kezepides, 1976; Bru 2006, Killian, Hofer and Kuhnle, 2012). Specifically, these authors found that student behavior is linked to peer influence, relevance of class materials, incentives given and student demographics. 
Putnam, Horner and Algozzine (2011) stated that students with problem behaviors are more likely to have academic deficiencies. These students represent an area of concern for schools, as they are often not able to fully embrace or appreciate education. As a result, Rhule (2005) stated "problem behavior poses personal and economic cost for youth's victims and families, as well as for taxpayers" (p. 1). This style of research is valuable, but is often isolated to urban and low-income schools. These traits are common among all students regardless of background. It is the aim of my research to determine the ways in which PBI can assist students of high-income schools. It is essential that students are able to learn self-regulation in schools as it can have long-term impacts on society-consider all the times you have ever thought that a rich person acted irrationally or outside of what is considered normal. We often emphasize the important of schools in empowering and prepping low-income youth for society, yet often do not for affluent students.

\section{Benefits and Detriments}

A classroom is supposed to be a place of learning and collective growth within all schools. In high school, that dynamic is a bit different as students have higher degrees of personal knowledge and have developed their sense of personal identity. Because of this, Sugai and Horner (2000) claim it is difficult to teach behavior in high school. Class management at all levels is critical, but as students get older the importance has stronger ramifications for teachers. Several studies such as Rhule (2005) quoting the American Psychological Association found that conduct problems are the most common child behavior disorders with prevalence rates ranging from $6 \%$ to $16 \%$ of boys and $2 \%$ to $9 \%$ of girls. As a result, it is necessary that teachers have a plan in order to deal with the common and non-common behaviors that arise. Polirstok and Gottlieb (2006) found that there should be grade level specific techniques. Yet commonly classroom management plans are not tailored to the students, but to the teacher. It is important that students regardless of background are given optimal learning conditions. PBIS is guided by an integration of data based decision-making, measurable outcomes, evidence-based practices and systems for accurate and sustained implementation (Sugai and Horner, 2009). Each of these factors supports the implementation of PBIS to assist in the development of positive behavior within the classroom.

While the system of PBIS includes implementing and assessing universal interventions (Hawken \& Horner, 2002; Leedy, Bates \& Safran, 2004); Operant Conditioning (Kazepides, 1976) found the opposite-education is a convenient instrument for correcting social, political or economic evils. Concluding, PBIS is not for the benefit of the student, but instead to assure students fit their role in society and do not deviate from the current societal structure. I argue that if the goal is to correct social, political, and economic evils, it is imperative that students of all backgrounds are oriented toward respecting collective success and resulting in even further individual prosperity. Systems that are meant to alter student behavior such as PBIS can have aversive impacts on students (Rhule, 2005; MacLean-Blevins, 2013; Singer, 2014; Kazepides, 1976). Specifically, Rhule (2005) found that programs oriented toward group intervention can have iatrogenic effects. These unintended impacts create a difficult ethical situation, as we must decide whether the data is worth the harm it can cause to research participants. However, student behavior and educational outcomes are more valuable to understand even with this potential cost. Long-term success for students and an understanding of ways to improve education within high-income schools is invaluable.

Singer (2014) found that such systems simply reward students for obedience. While Class DoJo: Supporting the art of student self-regulation (MacLeab-Blevins, 2013) found that students lost part 
of their internal motivation to learn because of (PBIS); Academic Achievement and the Implementation of School-wide Behavior Support (Putnam, Horner \& Algozzine, 2011) found that student productivity and participation increased as a result of rewards. It can be argued that systems such as PBIS work to create a uniform student body and eliminate the unique qualities they possess. I proclaim that every student deserves an opportunity to learn and systems such as PBI can create an environment that promotes this understanding. However, one must consider the end goal to guide decision-making. If the goal is to prepare citizens for the world, we cannot ignore PBl's potential to empower students of high-income as agents of change, just as we use it to organize and empower low-income students. The potential to positively impact student behaviors cannot be ignored without first determining the validity and effects of negative impacts a PBI system may present.

\section{Academic Impacts}

I argue that the primary goal of school is to create academically sound and culturally aware citizens prepared to be successful in society. As noted by Warren et al. (2003), "Positive behavior support includes a broad range of systematic and individualized strategies for achieving important social and learning outcomes while preventing problem behavior" (p. 80). This approach leads to at least three outcomes for students: (1) improved academic achievement, (2) enhanced social competence, (3) safe learning and teaching environments (Bohanon et. al, 2006; Office of Special Education Programs, 2002). As a result, the implications of PBIS on academics are clear. The enacting of such a program has to potential to enhance education for all parties involved in the process. The classroom environment is critical to the overall success for students (Bohanon et al., 2006; Kilian et al., 2012; Bru 2006; Putnum et al, 2011).

\section{Internal Aspects}

Every student has the ability to learn given the right circumstance that provides him or her with all the necessary resources. Student behavior and academic outcomes are heavily related to one another (Putnam et al, 2001; Polirstok and Gottlieb, 2006; Bohanon, 2006; Kilian et al., 2012; Bru 2006). While Bru (2006) found that relevance of schoolwork to a student's life had a significant role in student in-class behavior; Polirstok and Gottlieb (2006) found behavior was more related to student's idea of achievement value which describes the value for success, future goals and hard work instead of leisure and social activities. For both these factors impact several areas of student life. This is true of all students, yet the focus on improving student behavior is too often limited to low-income students. The accessible research fails to investigate the ways in which this can benefit short and long-term behaviors in high-income students. As a result, the benefit of PBIS on this student population is not effectively understood.

\section{External Aspects}

The environment that is so critical to student success is impacted by countless factors. Several studies found that interpersonal relationships have an extreme impact on student behavior (Kilian et al, 2012; Bru, 2006; Spera, 2006; MacLean-Blevins, 2013). Specifically, MacLean-Blevins (2013) stated "student behavior can be understood through the motivation, reinforcers, and punishments imposed upon students by the teacher." In contrast Spera (2006) found that parents had a significant role in the success of the child. In both cases there is a focus on relationships between students and the adult community as factors in their academic successes and/or failures. The connection between teachers and parents is a critical interpersonal relationship in the process of 
educating students. Students respond in countless ways to differing teachers, as their relationship with the teacher weighs heavy in interaction patterns. In the case of high-income students it is important that a structure is implemented that fosters positive relationships between students and teachers. This makes it necessary for these students to not be ignored in research as it regards the impacts of further developing these relationships on academic outcomes.

Polirstok and Gottlieb (2006) found that teacher referrals are often related to academic performance because students removed from the classroom receive less instructional time. As determined by Putnam et al. (2011) these students lose about 20 minutes on average of instructional time every class from which they are removed. Due to this, students miss an opportunity to learn concepts and thus are worse off than peers. The goal of PBIS is to create a system that prevents problems before they occur or to diminish severe forms of conduct problems before they progress to full-blown disorders or delinquency (Rhule, 2005). Disciplinary issues are not solely limited to low-income schools. Students from high-income backgrounds also deal with restrictions in learning opportunities. PBIS provides school communities a way to reduce disruptions ad lost time in the classroom and increase opportunities to enhance further learning.

Kilian et al. (2012) recognizes an even stronger student behavior influencer, peers. Students spend more time daily interacting with peers than with any teacher. As a result, their input impacts each other's behaviors heavily. Berndt and Keefe (1995) stated "students become more involved in classroom activities throughout the school year when they perceive their friends as being involved, they become more disruptive when they perceive their friends as being disruptive." As school is a social and academic institution, Bru (2006) noted that as students believed going against school norms would increase peer status, demonstrated more off-task behavior. Overall, these negative aspects of student interpersonal relationships have a drastic impact on classroom and school climate. The usage of PBIS includes implementing and assessing universal interventions that create a collective set of norms to assure a positive school environment (Horner, 2002; Leedy, Bates and Safran, 2004). In an effort to promote a positive school environment, aspects of students' culture have to be transformed to meet expectations that foster collective and personal growth. Society as a whole depends on the success of schools and steps must be taken to provide tools that foster educational success. I argue that PBIS can benefit students within high-income schools as they are not absent of student influence. These students must have an environment that fosters positive behavior development just as lower-income or low-performing schools do.

\section{Technology}

As society moves further into the $21^{\text {st }}$ century, schools must further embrace technologies of the time. Schools use technology to outline curriculum, collect attendance, and keep records of students' grades and much more. However, our techniques for connecting schools and the students' home lives remain a work in progress. In my experiences the cost of educating teachers regarding technology is a significant factor in whether new systems are introduced effectively. This does not excuse teachers that resist changes because it requires a usage of new tools and a departure from past practices. All together this creates a negative ideology barrier between education and incorporating $21^{\text {st }}$ century technology.

\section{Privacy}

The debate about privacy expands through countless facets of society; people, places and ideas are continually connected. The growth of the web and the economic benefits of web data and 
varying kinds of applications cannot be ignored. All this connectedness brings to light the possibility of privacy issues and access to sensitive information (Singer, 2014). However, using online programs as a part of PBIS can allow parents immediate access to student behavior on a near instant basis due to advancements in technologies. It takes into account our fast-paced society reducing the old-school practices of direct parent and teacher conferences. As technology continues to improve teachers and schools must allow technological tools to assist in the educational process.

\section{Conclusion}

After reviewing and analyzing prior research on the implications of PBIS and its role in influencing student behavior, the potential benefits of PBIS are clear. This system provides students with an environment that is beneficial to personal and collective development. However, there are concerns of unintentional harm within this system. Students can be categorized as badly behaved, treated unfairly due to perceived behavioral outcomes, and in cases indoctrinated, lose their personal curiosity and liberty through having such uniform expectations. Student behavior is based upon several factors including interpersonal relationships with peers and adults in their lives, academic expectations, perceived relevance, and general view of school as a whole. In order to promote an environment that provides students with opportunities to find themselves, we must as teachers and academic institutions foster positive behaviors to assure educational growth can occur. This reality is true for all students and to better provide a society that values order and common good, it is essential that every student is given similar expectations for behavior. I argue schools are the common ground that can assist societies in assuring that socioeconomic status is not the determiner of behavior in school or in larger society. The systems of PBIS provide a structure for students that can have positive ramifications into the future. As the technologies of the $21^{\text {st }}$ century advance, it is critical for educational institutions to take advantage of tools that connect students, parents and teachers.

\section{Methodology}

The study is being conducted in a private school outside of the United States. More specifically, the setting is a private American school located in Kuwait. This school has an American curriculum that is adjusted to reflect social expectations and course content as needed in an Islamic nation. The school features a minority of licensed teachers and a majority with no teaching background at all. There are financial incentives given by the government for educational achievement that serves as an external motivator.

The focus group for my study is a group of $12,10^{\text {th }}$ grade male students in a world history classroom. It consists of boys age 15 and 16, respectively. This group is composed of several wealthy students that will have luxurious lives inevitably and students that are middle-class. Staff within the school have deemed these students challenging. Student abilities range from above average to below average academically. Their behaviors vary as well; some can ruin a lesson, while others are focused, but can be swayed by the behaviors of others. These students were systemically isolated from other tenth grade male students. A few students will not be returning to the school next year, either by choice or administrative decision. As a result, they have taken to higher levels of disruption due to the lack of future consequences. It is expected of teachers to navigate the negative behavior until their eventual absence. 
This group is essential in this study as they represent a grey area for research in behavior intervention. There is little information about the influences of implementing PBI on rich and private school students alike. The goal is to create a data source for teachers working in such environments to reference in cases to establish behavior management in such settings. This demographic is underrepresented and as countless educators work in these setting, it is valuable to have tools and strategies specific to this context to be assist with creating a constructive learning environment.

In order to analyze the impacts of the study, I will collect varying data types. Student interviews will be conducted to learn student beliefs on behavior influences. This will include: perceived and actual influences on behavior, a personal journal on day-to-day or weekly behavior patterns, academic outcomes throughout the study, and student behavior outcomes daily. These sources of data will allow for an in-depth analysis of the causes and impacts of implementing PBS within the classroom.

There will be four tools used for data collection to investigate the research question and subquestions. First, students will take a survey to investigate factors that determine their behavior patterns within the school. This survey is meant to examine things influencing student behavior and ways that students mitigate these factors (Source 1 and Figure 1). Second, student behavior patterns during the research process will be collected using ClassDojo. This program stores information of given behavior based researcher inputs. It provides access to students and parents detailing daily classroom behaviors. The areas of compiled data include two categories; personal interactions and group interactions. Specifically, it covers aspects of preparedness for class, participation, engagement, tardiness, teamwork, bullying and disrespectfulness (See Source 2 and Figure 2). Thirdly, there is an analysis of student grades before and after the implementation of intervention programs. The information is derived from my gradebook and will be displayed before and after the intervention of the program. It will display the four categories from the gradebook: homework, classwork, quizzes, and tests. The goal is to determine whether academic outcomes changed as a result of the intervention program (Source 3 and 4). Lastly, a teacher feedback survey will be conducted to determine whether student behavior changed in other classrooms during the implementation period (See Figure 4).

In order to provide a clear analysis of student behavior patterns before and after incorporation of the intervention strategies, the process will be done over about a ten-week period (See Figure 5). It is critical to collect credible data that depicts students' behavior patterns before the input of the behavior adjustment strategies. After this period of information is collected, there will be a fourweek period in which students have knowledge of behavior tracking. This allows for an understanding of the data and gives the potential for improvement in students. Once these two phases are completed, there will be time to determine whether behavior regression occurs. It creates a window to examine behavior in other classrooms by talking with teachers and logging feedback. This window of time reduces the impacts of the usual student increase in academic outcome near grading periods and downturn as a result of school breaks. Overall, this timeline creates a clear organization of baseline data collection, impacts of interventions, and-post experiment observations.

A balanced approach as both the teacher and researcher is critical in this experiment. In order to do so, I have limited my examination of student behavior patterns to independent work time. This creates a separation between teacher time and researcher time. I believe the balance is not difficult to attain because as teachers, we are researchers every day that interaction with students occurs. However, collecting data can be difficult, especially in regards to behavior patterns. The behavior 
input time is limited because it requires the data to be concise and calculated based on a complete observation instead of an immediate reaction to a given behavior. Students during research may exhibit behaviors that require intervention, but for the sake of research it must be avoided. As a result, there is a threshold for behaviors that can be logged, but in cases of safety issues or abuse in varying types; these students will be removed from class. Overall, after each day or week of research, a journal entry will be noted to describe the class setting and the circumstances surrounding data collection. These aspects assure that data is credible and conflicts between research safety and health concerns are handled according.

\begin{tabular}{|l|l|l|l|l|}
\hline Research Question: & ClassDojo & $\begin{array}{l}\text { Student } \\
\text { Survey }\end{array}$ & $\begin{array}{l}\text { Gradebook } \\
\text { /Graphs }\end{array}$ & $\begin{array}{l}\text { Teacher } \\
\text { Survey }\end{array}$ \\
\hline $\begin{array}{l}\text { How does implementing positive behavior intervention supports increase positive student } \\
\text { behavior and impact student self-regulation within my classroom? }\end{array}$ & $\mathrm{X}$ & $\mathrm{X}$ & $\mathrm{X}$ & \\
\hline Does this system change student classroom awareness and overall engagement? & $\mathrm{X}$ & & $\mathrm{X}$ & \\
\hline Is there an increase in academic performance? & $\mathrm{X}$ & & $\mathrm{X}$ & \\
\hline Is there carry-over into other classrooms? & & & & $\mathrm{X}$ \\
\hline What happens to behavior after the program is removed? & $\mathrm{X}$ & & $\mathrm{X}$ & \\
\hline
\end{tabular}

\section{Data Analysis \\ Description:}

The purpose of this research was to determine the influence of implementing positive behavior strategies, PBI/PBIS, within my $10^{\text {th }}$ grade history classroom. In order to conduct accurate research, I spent one-month collecting base data to compare with the research findings. The areas of focus were: instances of positive behavior as determined by a specific areas of focus, levels of engagement, academic performance, carry over into other classes and the impacts of removing the program being used. During the research behavior was recorded to determine the patterns of behavior with knowledge of the ClassDojo program being used to track behavior. In the implementation period, data was collected to evaluate whether student behavior was altered as a result of the PBI program initiated. Specifically, the ClassDojo system was used to note occurrences of positive and negative behavior occurrences. This data was collected and was compared to that from the pre-research data collection. Along with the collection of behavior statistics, student academic performance was monitored. As a part of the research, it was a goal to decipher whether behavior changes impacted academics.

Every day during the research period, student behavior was tracked to determine whether they had class materials, were on task, participating during given times, arrived on time, and if other behaviors either negative or positive were occurring. Each day, students were monitored during independent work time. This time was after instruction had been given and students were to act as 
independent learners. Students were given the benefit of a redirection before the information was input into the system. However, after redirection, if the student behavior persisted it was placed into the system based on a determined category of behavior patterns. At the beginning of the week student scores were displayed to the class and we discussed ways for students to improve or maintain. After the first day, the responsibility of monitoring behavior was on the student and parents. The student with the greatest improvement was the winner of a student of the week award. This student was afforded a chocolate bar and recognition by the class for a brief moment before the lesson began. This outside incentive was to provide recognition for positive behavior whether a student was always positive or had a turnaround in behavior patterns. Overall, during the research project, I collected data about behavior patterns and used these patterns to examine the potential link between behavior patterns with a support system, the role PBIS can have on academic performance, engagement, and behaviors outside of the classroom.

\section{Data Examination}

The data collected was examined in numerous ways. Each aspect of analysis was related to the area in which the data was to be used. First, the student survey was to determine the most influential factors in student behavior. It is compiled into a graph that depicts the areas of sway that impact student behavior patterns. Next, there was a collection of baseline data, which would later be compared to information compiled during the PBIS implementation. This data was collected using ClassDojo. This program linked parents, students and me (the teacher) in the behavioral monitoring system. The intent was to determine whether students were more or less engaged as a result of the PBI system incorporated into classroom management. Next, I tracked academics before and during implementation. The goal was to determine if academics increased as behavior patterns changed. This information was calculated and input into a graph. The information was collected on both a collective and individual basis. After, I conducted a survey of teachers to determine whether student behaviors changed elsewhere. This data was meant to determine student improvement over the given timeframe. This information was incorporated into a table to display altered or constant behavior patterns. Lastly, I monitored students without any mention of ClassDojo or PBI to determine whether behavior regressed or remained reasonable similar to that of the baseline collection period.

\section{Findings:}

\section{Source 1: Student Survey}

\section{Student Influence Survey}

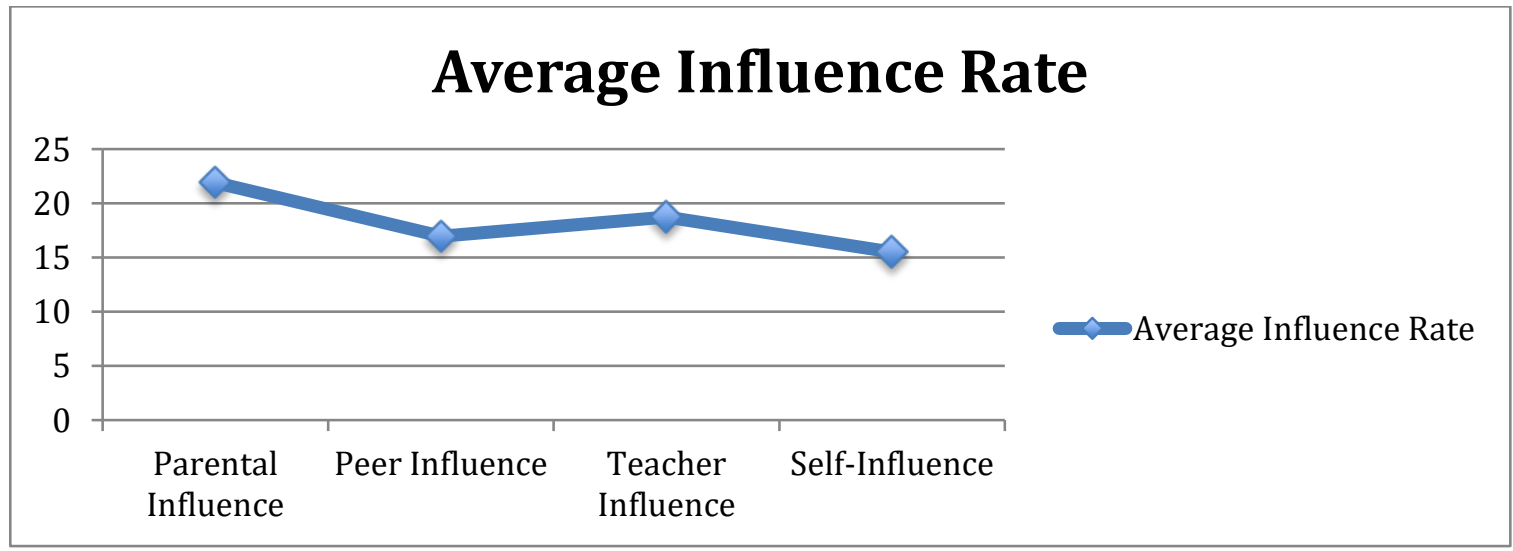


The input of students is critical to understanding their actions within a classroom. TO support this, I conducted a survey to determine their beliefs about behavior patterns. In examining the information, I found that (58\%) of students believe teachers are most impactful on behavioral outcomes. The remainder of students (42\%) indicated parents as most influential.

In the final calculation, peers rated third for their impacts. Students rated their personal influence as last on (58\%) of surveys. After data collection, I recognized that students viewed external factors as the leading determiners of behavior. Specifically, behavior is strongly impacted by interpersonal relationships with adults. The students within my school transition from class to class together, the changing component being the teacher. Based on the data, the behavior of students from class to class has potential to vary greatly. As a result, I believe the behavior of students from class to class could be different once the teacher survey is conducted. The data further shows that the teacherparent relationship is critical to student behavior potentials. However, I find it interesting that being with the same group of students every hour within school does not impact student behavior to a higher degree. One could argue that this aspect of their lives is constant and due to this their behavior is static until further external inputs move behavior from this static state. Overall, the student survey provided insight into perceived influences and indications of potential group through outside influence on the students.

\section{Source 2: Class Dojo}

\section{Class Behavior-Pre-Implementation Observation Figure 2a}

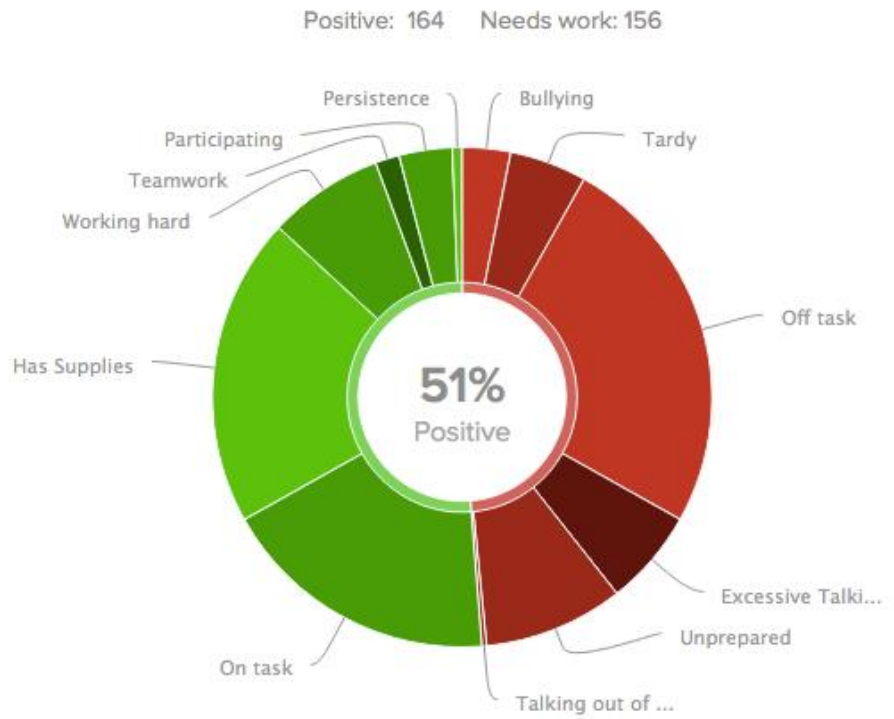




\section{Class Behavior-During Implementation: Figure 2b}

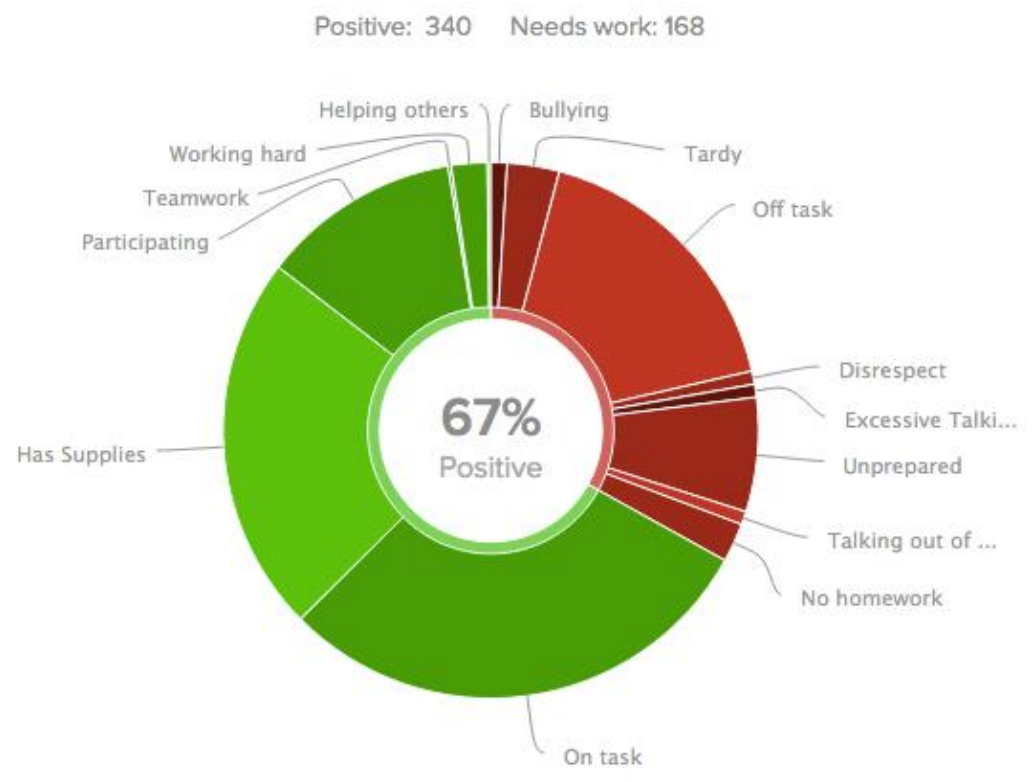

\section{Individual Student Data: Figure 2c}

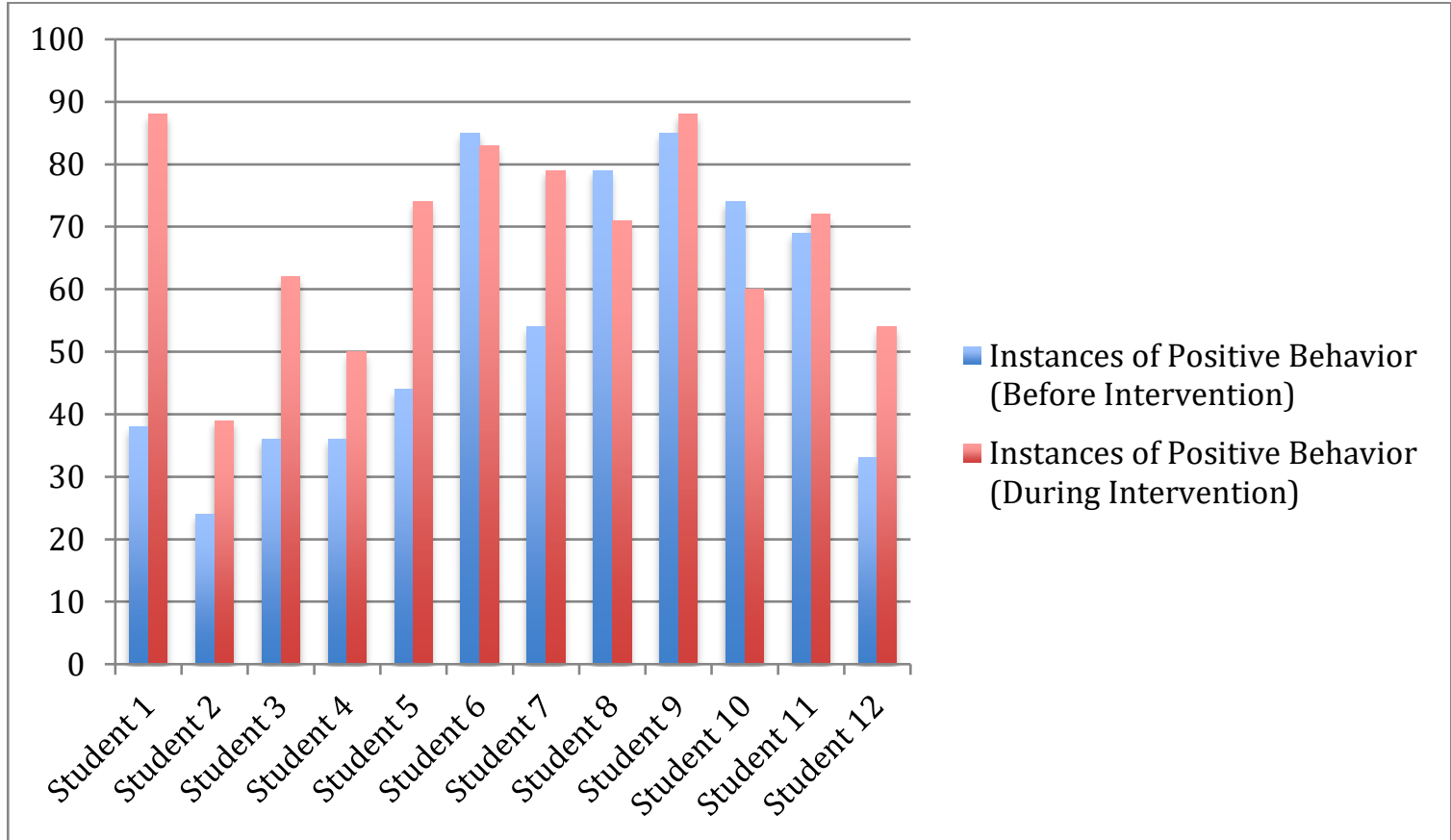

The monitoring of student behavior was critical to determining the impacts of positive behavior interventions. In analyzing the data, I was able to recognize trends in behavior patterns between the baseline and intervention data. The base data (See Fig. 2a) displays student behavior patterns 
prior to implementation. The original information displays that $(51 \%)$ of behavior was positive. Students demonstrated a high degree of bringing supplies to class, being on-task was common to a degree, and working hard which is determined by working consistently without issue was slightly common as well. The level of off-tasks behavior was high for students. The instances of excessive talking and talking while ignoring redirection were a slight issue. Overall the class was nearly evenly split between positive and negative behavior traits.

The individual student data is presented in Figure 2c. This calculates independent level positive behaviors. It shows student competency based on the criterion that was used to calculate the collective scale. Some students are registered highly in positive behavior. This included bringing materials, being on task, and working effectively. However, others that represent lower positive behavior comprised a high portion of the off-task behaviors-tardiness, and arriving to class without supplies. This information was collected to compare to the potential changes of implementation.

The implementation period of the ClassDojo program was used to determine the impacts of the PBI system within my classroom. At the beginning of every week, students were allowed to see their scores in class to ask questions and clarify standing. After that, it was students' responsibility to know their scores. Figure $2 \mathrm{~b}$ presents the findings for the class as a whole and Figure $2 \mathrm{c}$ displays individual student data. During implementation there was an increase in focus. Students were more engaged while exhibiting fewer instances of off-task behavior. This resulted in a higher amount of assignments completed. During this period students brought supplies to class more often. This impacted not only their ability to do assignments, but also understanding and quality of work. There was an extensive increase in student participation during this period as well. Generally, students shied away from responding to their bell ringers (beginning of class assignments) aloud. However, during and after the implementation window, student participation for this aspect of class is nearly $100 \%$. I cannot be certain, if it is because of the recognition that this facet was part of the ClassDojo calculation or general interest, but I do recognize a change since implementing the program. Overall, I noticed a general change of behavior in the classroom. Students were more engaged overall, more receptive of lessons and generally more positive in the classroom.

The data presents a growth in positive behaviors displays, yet regressions occurred as well. During the intervention period, a few students failed to complete homework assignments. This cannot be directly attributed to the program, but this behavior was not an issue prior. There was a reduction in off-task behavior, yet there is still a need to assure students understand that a warning means reduce talking permanently. The level of unpreparedness remained near constant based on the data. The amount of students that arrived to class prepared increased, yet students that came to class without supplies kept the data constant. There was one instance of disrespect as a student was removed for excessive talking and bullying. The student failed to leave promptly and at one point refused to exit. However, after further prompting the student left without issue and later apologized.

On the individual basis, every student improved in varying ways. Some students that scored low during the base platform demonstrated high-level positive behavior change. High change is considered an improvement of $25 \%$ or more (see figure 2 c). In this case, student $1,3,5$, and 7 or $(33 \%)$ of students displayed significant change. These students increased their aspects of positive behavior through being on-task, participating, and coming to class with supplies. Other low scoring students improved their scores as well. The change that was displayed by these groups ranged from $14 \%$ to $21 \%$. These areas of improvement were not significant, but altered classroom 
dynamics for the most disruptive students. The data for student 2 , the lowest in the base data and during the intervention period, is marred by absences, suspensions, and a disregard for the implementation period. This student from the beginning and throughout the program did not seem altered or influenced by the intervention program.

As it regards the higher scoring students from the base data, there was minimal change. These students maintained or slightly improved their behavior patterns. However, in the case of student 10 , this student had a reduction in positive behavior. This student, though still behaving positively, dealt with issues of remaining on-task at times and bringing supplies to class. Overall, PBI had little impact on high scoring students' overall behavior. Their behavior was positive and, as a result, the higher level of impact was on students that performed poorly. How does this impact the implementation of the ClassDojo system? The data shows these students do not adjust behavior to compensate for the lacking behavior around them and are able to perform regardless of immediate student influence. I argue that these behavior patterns for the class and the students individually should lead to an increase in academic output. Overall, behavior improved, yet within the individual data certain behaviors were reduced while others remained nearly constant.

\section{Source 3: Student Grades (Class Averages)}

\section{Figure 3}

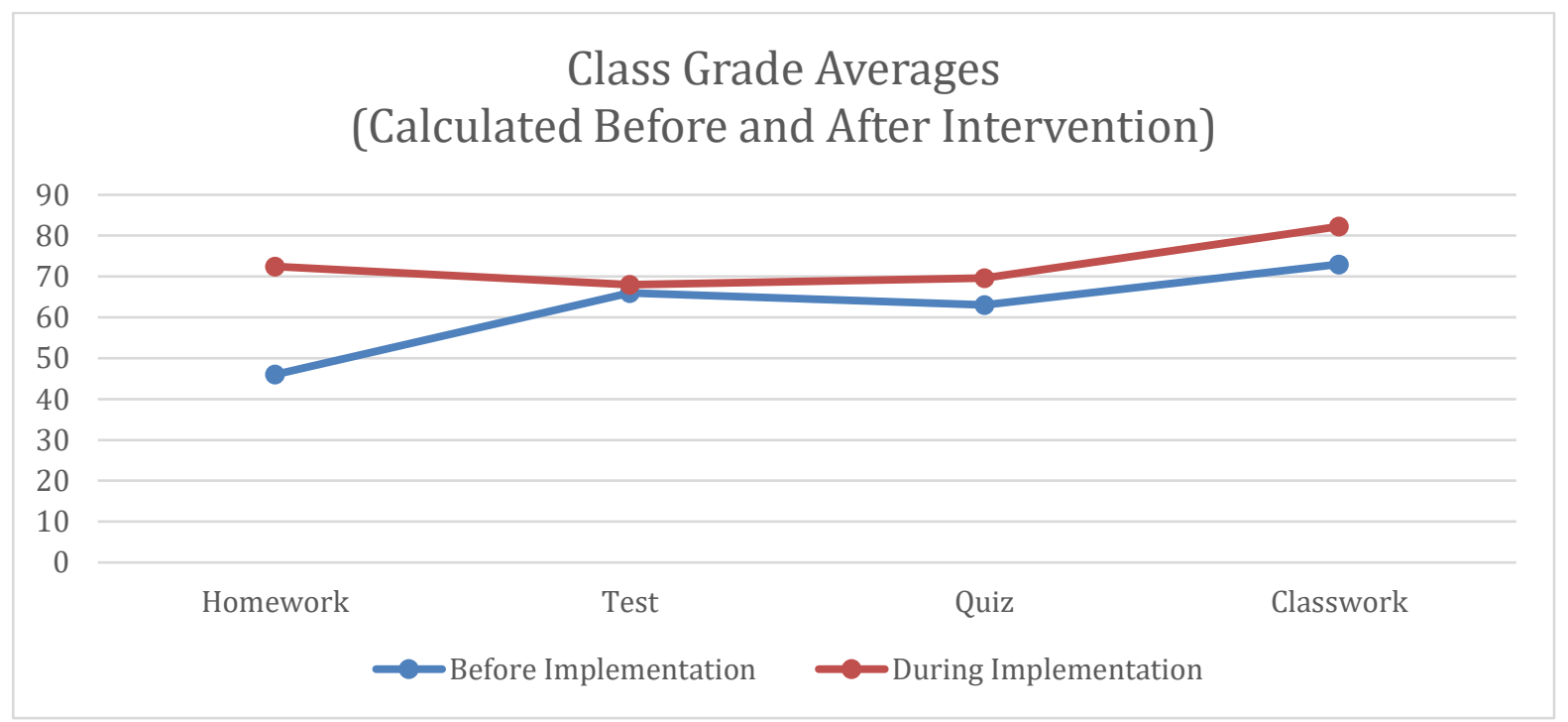

The relationship between student behavior and grades is evident. Students that behave well have the potential to outperform students that do not. This reality influenced my investigation into the correlation between grades and behavior patterns. The data collected before and during implementation is displayed in figure 3 . The base data demonstrates that students' average on homework was (46\%), tests (66\%), quiz (63\%) and classwork (73\%). The average for classwork is reasonably higher than others. These assignments are presented in class and at a higher frequency than others. I conclude that these assignments will most benefit from PBI as they occur within the sphere of direct observation. Students performed at an average level on classwork. The other assignments are based on materials completed in class and work outside of class. The quality of work for assignments completed solely in class was lower in part due to this reality. The performance on formal assessments is about comparable to the standard I have witnessed from my class. Only a few students requested a study guide and prepared prior to the day of the test. 
The issues of student homework completion exist regardless of environment. My students, as shown in Figure 3, were not exempt from such behavior. The students can turn in assignments at a reduced score, but most disregard homework. As a result, the baseline data demonstrates an "F" average for homework for the class. The baseline data prior to tracking the class demonstrates that student behavior as demonstrated in figure $2 \mathrm{c}$ and grades as shown in figure 3 display a link between behavior patterns and academic performance prior to PBI implementation.

The growth in positive traits as displayed in figure $2 \mathrm{~b}$ demonstrates a better environment. The data collected during the implementation shows class averaged of $(72.5 \%)$ on homework, $(68 \%)$ on tests, $(69.58 \%)$ on quizzes and $(82.5 \%)$ on classwork. The most significant gain was in the completion of homework. The issue during the baseline period was the quality of homework returned not a lack of competition itself. However, during the implementation period, the quality of work and amount of homework returned increased. The change between before and during the implementation period was $(26.5 \%)$ for the class average. The next highest change was an increase in the classwork average. As the study was underway, students' on-task behavior, participation and preparedness for class increased. I attribute the increase of these behaviors to the $(9.25 \%)$ growth between before and during the research. Students arrived to class during implementation more prepared and engaged than before ClassDojo was public knowledge. The overall demeanor of the classroom differed. The growth in assessment scores further supports the increase in engagement. The growth in quiz scores of $(6.58 \%)$ between the before and during period demonstrate an increased ability to perform. The increase of $(2 \%)$ for test average represent a positive change as well. The growth in engagement and test scores does not demonstrate that students' overall knowledge increased, but does demonstrate that with more engagement there can be an increase of academic output.

\section{Source 4: Student Grades (Individual)}

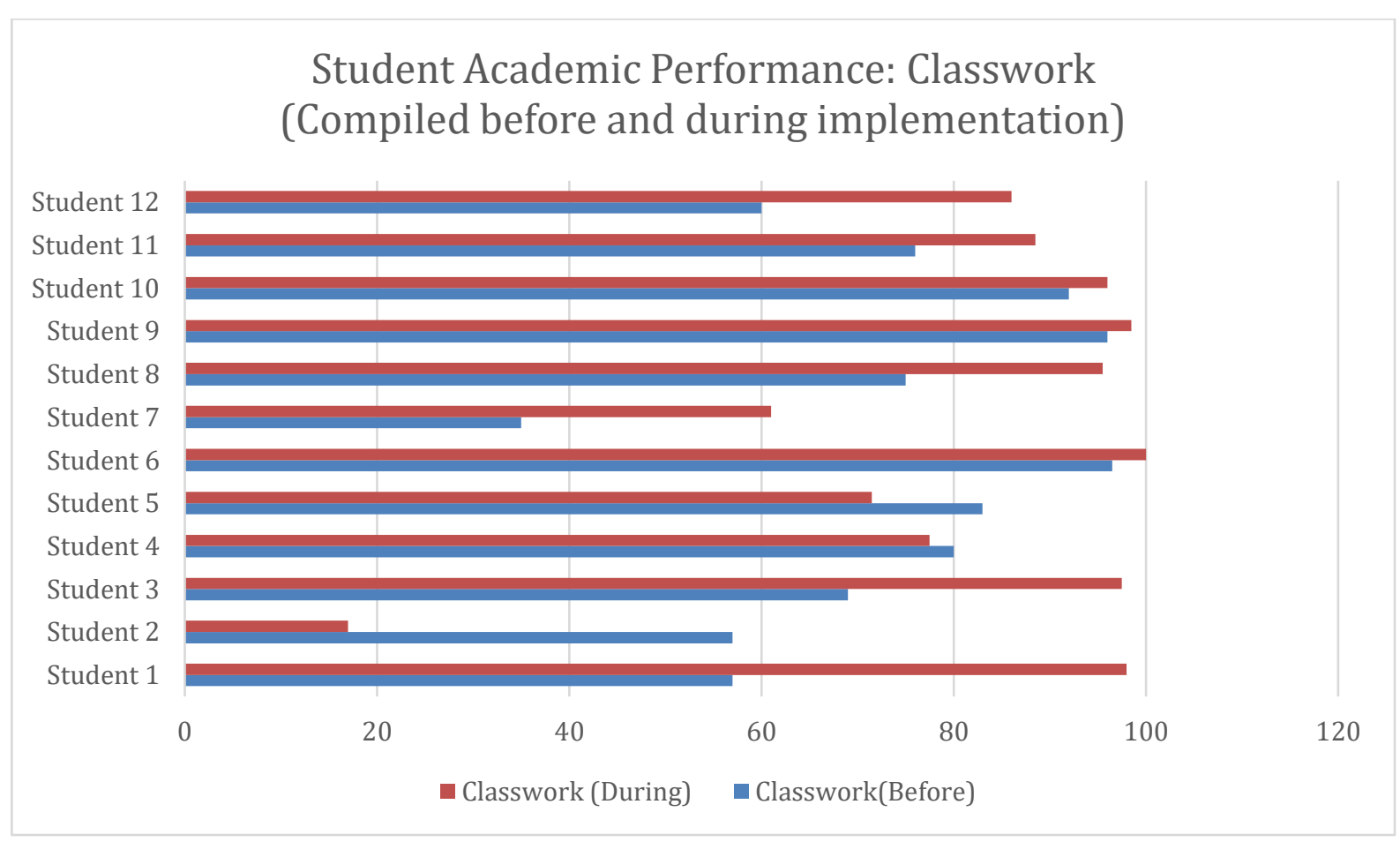



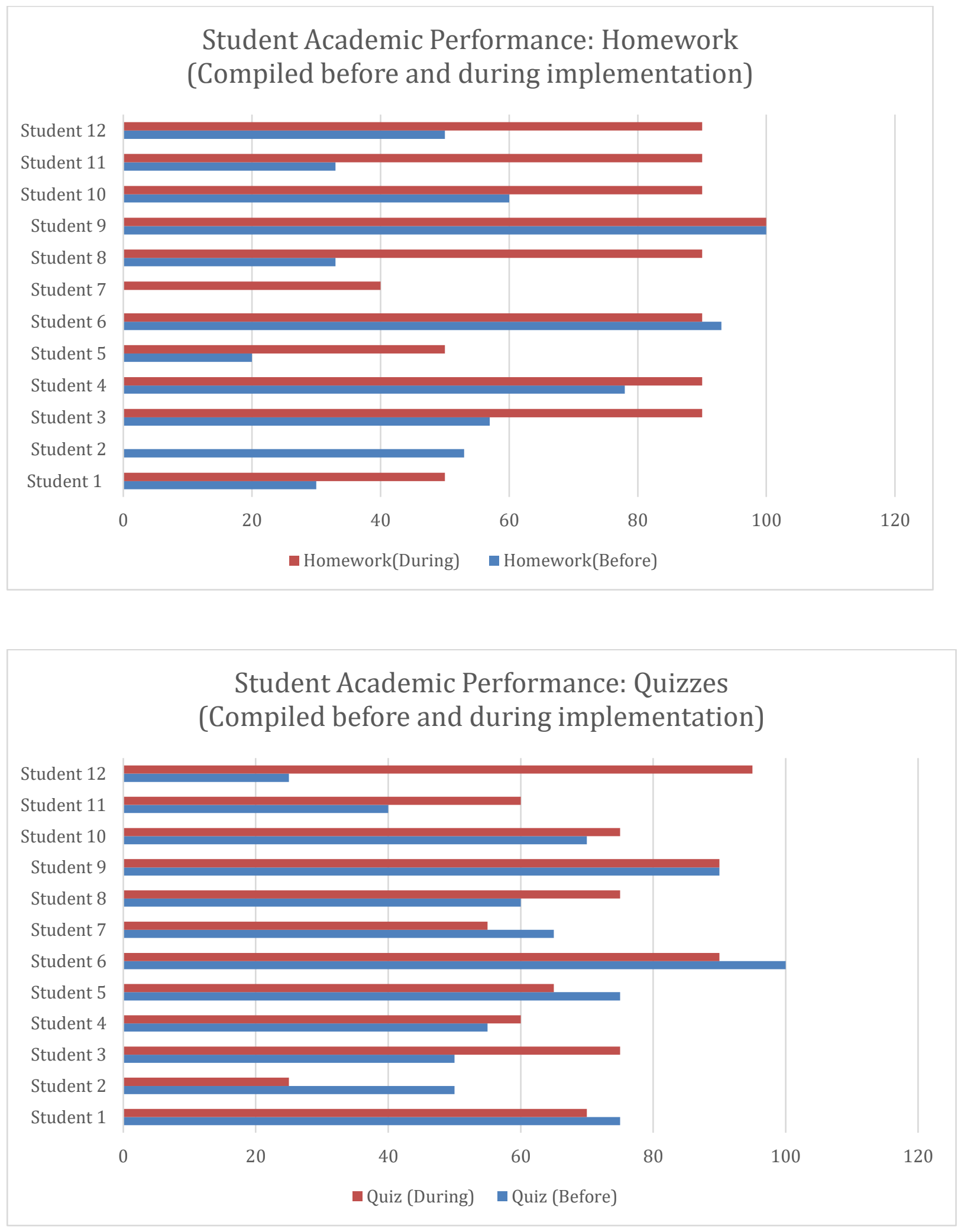


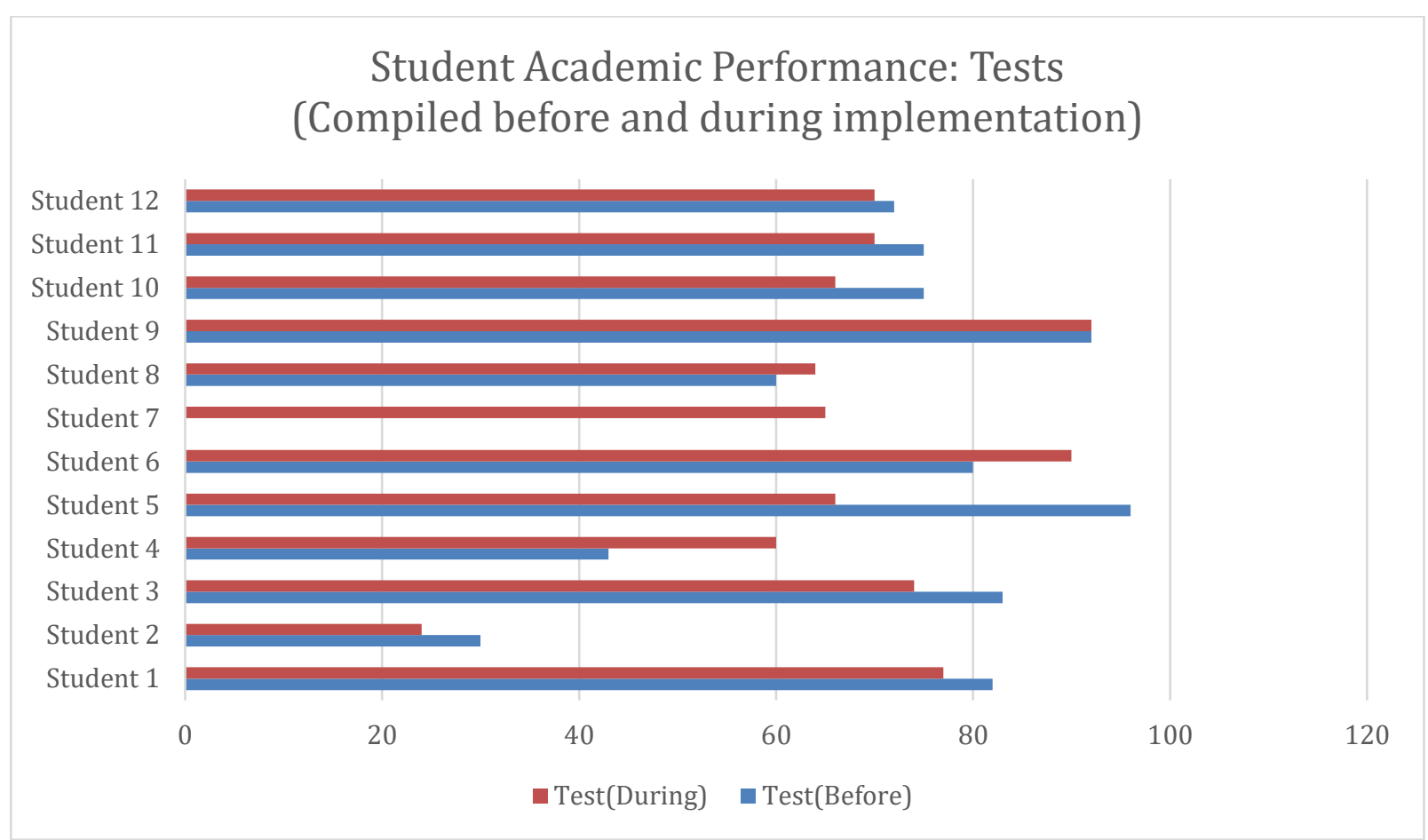

The growth in class averages can only be understood on the basis of individual changes. The information in figure $2 \mathrm{c}$ details the changes of individuals. If one evaluates this chart paired with source 4, it becomes apparent that students with more instances of positive behavior generally had higher academic output. Further, students with significant growth in instances of positive behavior displayed academic improvement. The outlier in the data is student 2. This student did not improve during the implementation. Instead student 2 regressed to levels lower than the baseline data calculations. As it regards testing, few displayed gains. In reality (42\%) of students maintained or improved in this area. In relation to quizzes: these scores improved or remained constant for (58\%) of students. Assessment changes varied based on participants involved.

The featured areas of improvement were classwork and homework. In fact, (83\%) of students had an increase or a static score in homework performance. These assignments are the reading guides that go along with course materials and require filling in information. However, student 6 displayed a negative change in homework performance. The change was not significant, yet the reduction should be noted. The outlier again was student 2 within this data set. Student 2 demonstrated a complete reduction in homework performance. This student failed to complete homework assignments at rates lower than base data levels. Again, this student displayed the lowest level of positive traits before and during the implementation period and demonstrated little positive change. Overall, the homework performance improved or remained generally constant.

The classwork improvement demonstrates the impacts positive behaviors have on academics. The class displayed an increase in student in-class assignments for $75 \%$ of students. The range of change varied from $51 \%$ to $2.5 \%$ depending on the student. The students that demonstrate a high level of proficiency grew slightly. Lower performing students displayed various improvements. Each of these students within the data displayed a growth in positive behavior traits. The other students that had an increase in positive behavior demonstrated a reduction of output. Students 5 and 4 both had a reduction in performance. This reduction for student 4 was only $2.5 \%$, yet student 5 decreased $11.5 \%$. In the case of student 5, quality of work decreased. Again, student 2 displayed 
an extensive regression (40\%). This was due to the lack of assignments being completed, absences and a disregard for the program. During the intervention period student academics outcomes remained constant or better for 11 of 12 students. Student 2 was slightly impacted by the implementation of the intervention program. However, this growth in positive behavior did not impact academic output. The data for behavior and academics supports the argument of a relationship between behavior and grades.

\section{Patterns}

The overall trends displayed a positive reaction to the implementation of positive behavior supports. Students collectively demonstrated a growth in positive behavior. This can be seen in Figure 2a-c, which displays the outcomes of the ClassDojo program. There was collective growth, yet the levels of change varied. High performing students were altered minimally. The academic outcomes followed a similar pattern. Lower performing students demonstrated academic improvement. The exception to this was student 2 . This student displayed a reduction in academic input. The students that performed behaviorally and academically high prior to implementation sparingly improved. This can be seen in source 4 and figure $2 c$.

The increase of positive traits for the class led to an increase in class averages. The amount of change varied (Figure 3); the largest increases were on assignments based directly in class. Classwork and homework are both directly related to class materials and are discuss in class. As a result, these areas were influence more directly by the behavior-tracking program. Another aspect that is shown by the data, but not by the student survey is that students may underestimate the impacts of peer influence. The classroom remained constant, yet student behavior changed, and as a result, created collective growth. The data supports a relationship between behavior patterns and academic outcomes. This relationship does not simply impact individual students; it impacts the entire classroom atmosphere.

\section{Conclusion}

The data supports the idea that PBI can transform student behavior. In most cases, it impacts students positively and allows for improvements. These improvements are more significant for poorly behaving subjects. These students have more voids for improvement and responded to this motivator. Behaviorally sound students demonstrate slight improvements, but remained at high levels of positive behavior. The data suggests those not displaying troubling behavior are only minimally affected. Academically, students displayed gains regardless. Again, students that displayed significant increases in positive behaviors displayed better academic outcomes, thus supporting the importance of PBIS in improving positive classroom culture.

Overall, the data confirms that behavior patterns and academic outcomes are related. Students are greatly impacted by external influences. These influences arise from varying aspects of students' lives. It is the responsibility of schools to bridge these gaps and provide environments that provide for the growth and educational progress. This does not guarantee that every student improves; yet gives every student an environment of positive behaviors and learning. The research supports that this is possible through PBIS. I argue that every school needs it regardless of the student demographics as we are preparing students to be citizens of the world. 


\section{Implications}

After researching, it is clear that PBIS can work within high-income and private school settings. It is critical to establish a system from the onset of school to solidify a culture of behavioral expectations. Through the research, I learned that the benefits of $\mathrm{PBI}$ cannot be ignored. The usage of PBIS improved the behavioral and academic outcomes of most low-achieving students. Students displayed a rise in engagement and therefore, students performed better in class. There was one student that was not truly impacted by the implementation of the program. The performance of this student improved in some areas, but there were regressions in most; this could be due to frequent absences during the implementation period. Further, the research shows that high performing students are minimally impacted by the incorporation of PBIS into the classroom. These students remained at levels similar to those displayed prior to the implementation period. At times, these students even displayed a slight regression in output. The case of this could be attributed to a missed or reduced scores on assignments.

There needs to be a better way to use PBIS to improve students that are high performing. The focus of PBIS is on low-performing students. However, little attention is given to students that already display positive behavior and high academic outcomes. Additionally, there needs to be an evaluation of the ways to impact students not influenced by PBI. These students may be a minority, but if the goal is collective improvement, no group can be ignored. What strategies can be used to adjust the program to those students that are impacted minimally by PBIS? How do schools guarantee that every teacher is equipped to implement and follow through with the PBI system? These questions are essential for understanding the program and the scope of impact. In order to better understand, research focus must shift to provide a more diverse area of study in relation to the usage of PBIS. The focus is limited to low-income or urban schools and as a result, other strategies and issues that may exist in other settings are not examined. Overall, the systems of PBIS should be used in all settings to test the applicability of the system and provide a complete foundation of comprehension for the settings that utilize it most.

\section{Conclusion}

The educational environment is complex and requires cohesion. I argue, the end goal is that every student has the opportunity to learn. As Kazepides states, "our goal is to design a better environment as the environment is critical not the person" (Kazepides, 1976, p. 56). There are varying factors that go into creating a successful educational structure. Often it is believed that money will solve all the issues of the educational process. I argue that students coming from affluent schools are placed at a disadvantage, if they are not given the appropriate tools to learn positive behavior. The intention of my research was to determine the impacts of positive behavior intervention supports within my classroom. Putnam, Horner and Algozzine (2011) stated that students with problem behaviors are more likely to have academic deficiencies. Students within my class are from high-income families, yet they are low performing academically. These academic outcomes, I believe are influenced by their behavioral issues. As the research shows, students behavioral patterns varied, yet lower-performing students also displayed negative behavior traits.

The usage of PBIS includes implementing and assessing universal interventions that create a collective set of norms to assure a positive school environment (Horner, 2002; Leedy, Bates and Safran, 2004). Once I created and implemented a system of PBIS that gauged students based on uniform behavior, it was my goal to track the impacts. Sugai and Horner (2000) claim it is difficult to teach behavior in high school due to their age level. Upon conducting my research, I noticed that 
once the system was in place students were more aware of the ways that everyone would be judged; it created an idea of equity among them. After students felt this level of equity paired with their competiveness it made them extremely responsive to behavioral influence. The overall goal of the study was to improve the classroom environment and promote a setting that benefitted learning for all. Singer (2014) found that such systems simply reward students for obedience. It was the choice of students whether to adjust their own behavior and my input was to compile data, and allow the class to function as normal. In certain circumstances, the point made by Singer can be true, yet it is dependent not upon the system, but upon the goal of the PBIS system implemented.

Spera (2006) found that parents had a significant role in the success of the child. During the intervention parents did not contact me. The students generally improved without the parentteacher partnership that is believed so critical. Almost all of the students either improved or maintained a high level performance. In other classrooms the situation varied. MacLean-Blevins (2013) stated "student behavior can be understood through the motivation, reinforcers, and punishments imposed upon students by the teacher." After conducting the teacher survey, I was able to determine if the growth made within my classroom was transferrable. Teachers within other classrooms noticed slight changes in behavior (see figure 4). There was a growth in students' desire to follow procedures and engagement. Whether this is directly related to the PBIS implemented in my classroom is arguable. Regardless, growth was noted in some areas during the implementation period. This information supports the idea that teachers highly influence student behaviors and outcomes.

Kilian et al. (2012) recognizes an even stronger input into student behavior outcomes, the influence of peers. I believe peers have the strongest impact on peer behavior, even though students argued otherwise. Berndt and Keefe (1995) stated "students become more involved in classroom activities throughout the school year when they perceive their friends as being involved, they become more disruptive when they perceive their friends as being disruptive." The research collected during this project supports the findings of Berndt and Keefe. As positive behavior patterns outcomes increased, a better classroom environment existed. Further, as disruptive behaviors increased, the easier it became for all students to lose focus. The majority of low-performing students improved and high-performing students remained near constant. The students that demonstrated growth in instances of positive behavior also had growth in academic outcomes. This can be attributed to fewer disruptions, promoting higher levels of engagement. The classroom environment is critical to the overall success for students (Bohanon et al., 2006; Kilian et al., 2012; Bru 2006; Putnum et al, 2011). The behavior of some students has remained at implementation levels, while others regressed. This could be a result of students adjusting to the program or students need for external motivation to perform better. However, after the implementation of PBIS within my classroom and evaluating the impacts, I believe that the classroom environment is essential to learning for all.

\section{Reflective Stance}

After conducting this research, I support the correlation between behavior and academic outcomes. As educators, it is our responsibly to teach students and to understand them as well. Teaching is a constant exchange of ideas and knowledge. It is essential for educators to create a partnership with students and that students are active participants in education. It is a critical responsibility of teachers to promote this partnership. As I move forward in education, wherever it leads me, I will remember the educational process is multi-faceted. Further, I will be more capable of incorporating PBIS into my classroom to improve the educational environment. On a larger scale, becoming an 
advocate for behavior strategies promoting holistic improvement. Overall, the systems associated with PBIS provide an opportunity to create an environment that fosters collective growth and learning for all students.

\section{Student Survey (Figure 1)}

Directions: Answer each statement by choosing the number reflects the influence each statement has on behavior decisions.

Name:

Date:

\section{Parent:}

(Least Impactful to Most Impactful)

My parent/s discuss my school behavior with me.

My parent/s discuss school with me regularly.

My parent/s have an impact on my behavior in school.

My parent/s care about my school success.

The way I behave in school reflects on in-home teachings.

Total: Add each row together to compile impact of this category.

Peers:

(Least Impactful to Most Impactful)

My peers discuss my school behavior with me.

12345

When my peers are demonstrating positive behavior I do better. 12345

My peers influence my behavior.

12345

My peers' opinion of me impacts my behavior.

12345

My peers see me as a positive student.

Total: Add each row together to compile impact of this category.

Teacher:

(Least Impactful to Most Impactful)

I behave differently based on the classroom teacher.

I behave better if I like the teacher.

My teacher discusses my behavior with me. 
My teacher encourages me to improve my behavior.

12345

My behavior is usually in response to teacher actions.

12345

Total: Add each row together to compile impact of this category.

Self

(Least Impactful to Most Impactful)

I behave based on the way I feel regardless of my environment. . 12345

I behave in certain ways because of classmates.

12345

I behave in certain ways because of the teacher.

12345

I behave in certain ways because of the course content.

12345

I behave in certain ways because of my parents.

12345

Total: Add each row together to compile impact of this category.

ClassDojo-Fourth Period-Figure 2a (Positive)

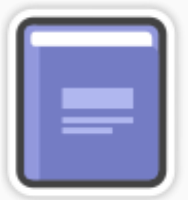

Has Supplies

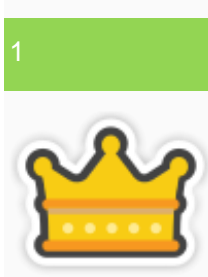

Helping others

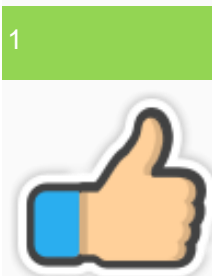

On task

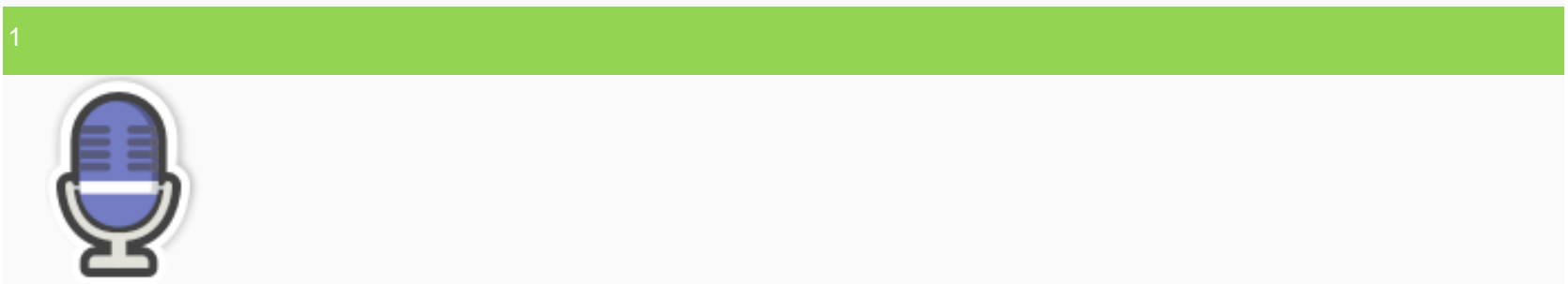


Participating

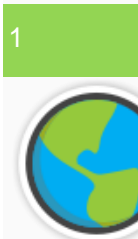

Persistence

1

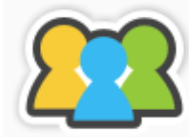

Teamwork

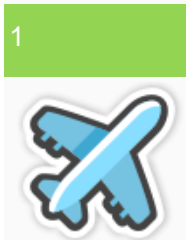

Working hard

\section{ClassDojo-Fourth Period-Figure 2b (Negative)}

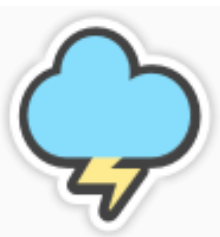

Disrespect

$-2$

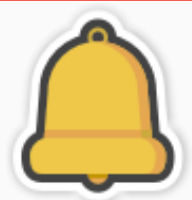

Excessive Talking 
$-2$

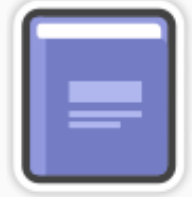

No homework

$-1$

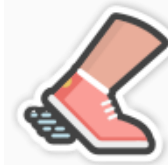

Off task

$-2$

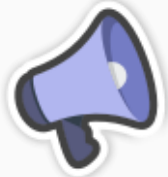

Talking out of turn

$-1$

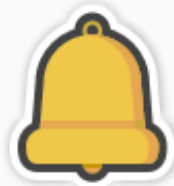

Tardy

$-2$

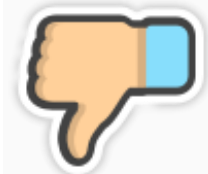

Unprepared

$-1$ 


\section{Teacher Survey (Figure 3)}

Class Behavior Survey:

(Least Impactful to Most Impactful)

Student behavior has generally improved over last four weeks.

12345

Student academic performance has improved over the last few weeks. 12345

Students have been more responsive to rule implementation.

12345

Students have been more engaged in lessons.

Students have generally had a more positive attitude.

Students have been more respectful.

Students have been more responsible.

Students have been more likely to come to class with supplies.

Students have shown an overall improvement.

Some students that were struggling have improved over the last four weeks. 12345

Total: Add each row together to compile impact of this category.

\section{Teacher Survey Results (Figure 4)}

\begin{tabular}{|l|l|}
\hline Teacher Survey Results & \\
\hline Behavior Survey & $\begin{array}{l}\text { Average } \\
\text { Rating }\end{array}$ \\
\hline Statement 1 & 2 \\
\hline Statement 2 & 2 \\
\hline Statement 3 & 3 \\
\hline Statement 4 & 2.6 \\
\hline Statement 5 & 3 \\
\hline Statement 6 & 2.6 \\
\hline Statement 7 & 2.3 \\
\hline Statement 8 & 2.6 \\
\hline Statement 9 & 2.6 \\
\hline
\end{tabular}




\section{Statement 10}

\section{*Based on American teachers surveyed.}

\section{Research Timeline (Figure 5)}

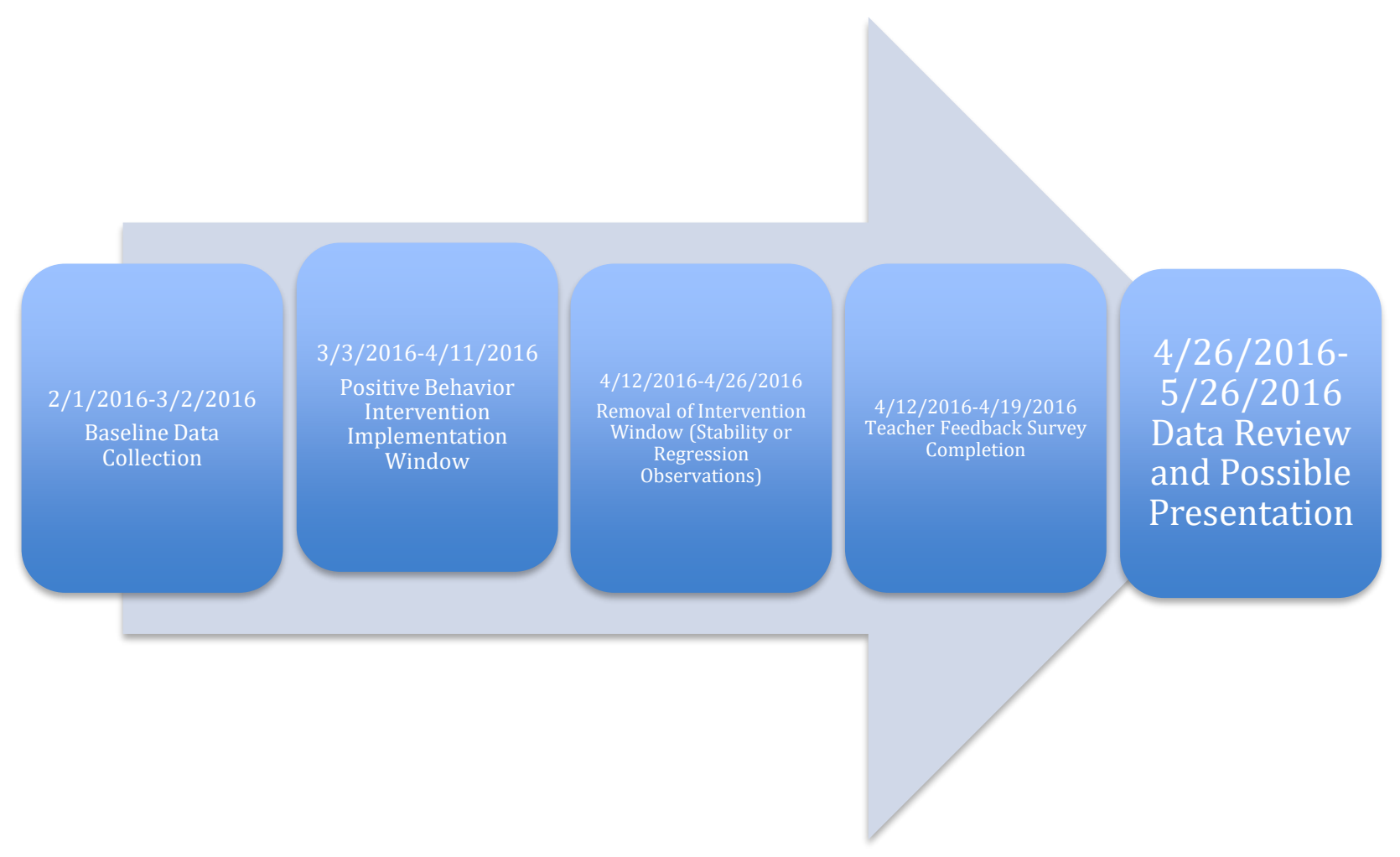

\section{References}

American Psychiatric Association. (2000). Diagnostic and statistical manual of mental disorders (4th ed., text rev.). Washington, DC: Author.

Bohanon, H., Fenning, P., Carney, K. L., Minnis-Kim, M. J., Anderson-Harriss, S., Moroz, K. B., . . Pigott, T. D. (2006). Schoolwide application of positive behavior support in an urban high school: A case study. Journal of Positive Behavior Interventions, 8(3), 131-145. https://doi.org/10.1177/10983007060080030201

Bru, E. (2006). Factors associated with disruptive behaviour in the classroom. Scandinavian Journal of Educational Research, 50(1), 23-43. https://doi.org/10.1080/00313830500372000

Hawken, L.S., \& Horner, R,H. (2002) Evaluation of a targeted group intervention within a school-wide system of behavior support. Eugene: University of Oregon.

Kazepides, A. C. (1976). Operant conditioning in education. Canadian Journal of Education / Revue Canadienne De L'éducation, 1(4), 53-68. Retrieved February 12, 2016, from http://www.jstor.org/stable/1494624

Kilian, B., Hofer, M., \& Kuhnle, C. (2012). Conflicts between on-task and off-task behaviors in the classroom: The influences of parental monitoring, peer value orientations, students' goals, and their value 
orientations. Social Psychology of Education Soc Psychol Educ, 16(1), 77-94. https://doi.org/10.1007/s11218-012-9198-y

Leedy, A., Bates, P., \& Safram, S.P. (2004). Bridging the research-to-practice gap: Improving hallway behavior using positive behavior supports. Behavioral Disorders, 29(2), 131-139. https://doi.org/10.1177/019874290402900204

MacLean-Blevins, A. O. (2013, June 24). Class DoJo: Supporting the art of student self-regulation. Retrieved February 10, 2016, from http://www.smcm.edu/mat/educational-studies-journal/a-rising-tide-volume-6summer-2013/

Office of Special Education Programs. (2002). Positive behavior support: Implementers' blueprint and selfassessment. Retrieved February 199, 2016, from http://www.pbis.org

Polirstok, S., \& Gottlieb, J. (2006). The impact of positive behavior intervention training for teachers on referral rates for misbehavior, special education evaluation and student reading achievement in the elementary grades. International Journal of Behavioral Consultation and Therapy, 2(3), 354-361. https://doi.org/10.1037/h0100789

Pound, K. (2013). Technology support for student behavioral development. Retrieved February 11, 2016, from http://eaglefeather.honors.unt.edu/2013/article/268\#figure_1

Putnam, R., Horner, R. \& Algozzine, R. (2011). Academic achievement and the implementation of schoolwide behavior support. PBIS Newsletter, Volume 3, Issue 1, accessed 2/10/16 at http://www.pbis.org/pbis_newsletter/volume_3/issue4.aspx

Rhule, D. M. (2005). Take care to do no harm: Harmful interventions for youth problem behavior. Professional Psychology: Research and Practice, 36(6), 618-625. https://doi.org/10.1037/0735-7028.36.6.618

Singer, N. (2014, November 16). Privacy concerns for classdojo and other tracking apps for schoolchildren. Retrieved February 11, 2016, from http://www.nytimes.com/2014/11/17/technology/privacy-concernsfor-classdojo-and-other-tracking-apps-for-schoolchildren.html?_r=1

Spera, C. (2006). Adolescents' perceptions of parental goals, practices, and styles in relation to their motivation and achievement. Journal of Early Adolescence, 26(4), 456-490.s[: https://doi.org/10.1177/0272431606291940

Sugai, G., \& Horner, R. H. (2009). Responsiveness-to-intervention and school-wide positive behavior supports: Integration of multi-tiered system approaches. Exceptionality, 17(4), 223-237. http://dx.doi.org/10.1080/09362830903235375

Warren, J., Edmonson, H.. Griggs, P., Lassen, S., McCart, A., Turnbull, A., et al. (2003). Urban application of school-wide positive behavior support: Critical issues and lessons learned. Journal of Positive Behavior Interventions, 5(2), 80-92. https://doi.org/10.1177/10983007030050020301 